\title{
Article \\ Mitochondrial Genomes, Phylogenetic Associations, and SNP Recovery for the Key Invasive Ponto-Caspian Amphipods in Europe
}

\author{
Tomasz Mamos ${ }^{1,2, *}$, Michał Grabowski ${ }^{1}$, Tomasz Rewicz ${ }^{1,3} \mathbb{D}$, Jamie Bojko ${ }^{4}$, Dominik Strapagiel 5 \\ and Artur Burzyński ${ }^{6}$ (D)
}

1 Department of Invertebrate Zoology and Hydrobiology, Faculty of Biology \& Environmental Protection, University of Lodz, 90-237 Łódź, Poland; michal.grabowski@biol.uni.lodz.pl (M.G.); tomasz.rewicz@biol.uni.lodz.pl (T.R.)

2 Zoological Institute, University of Basel, 4051 Basel, Switzerland

3 Centre for Biodiversity Genomics, University of Guelph, Guelph, ON N1G 2W1, Canada

4 National Horizons Centre, Teesside University, Darlington DL1 1HG, UK; j.bojko@tees.ac.uk

5 Biobank Lab, Department of Molecular Biophysics, Faculty of Biology \& Environmental Protection, University of Lodz, 90-237 Łódź, Poland; dominik.strapagiel@biol.uni.lodz.pl

6 Department of Genetics and Marine Biotechnology, Polish Academy of Sciences, Institute of Oceanology, Powstańców Warszawy 55, 81-712 Sopot, Poland; aburzynski@iopan.pl

* Correspondence: tomasz.mamos@biol.uni.lodz.pl; Tel.: +48-42-635-44-46

check for updates

Citation: Mamos, T.; Grabowski, M.; Rewicz, T.; Bojko, J.; Strapagiel, D.; Burzyński, A. Mitochondrial Genomes, Phylogenetic Associations, and SNP Recovery for the Key Invasive Ponto-Caspian Amphipods in Europe. Int. J. Mol. Sci. 2021, 22, 10300. https://doi.org/10.3390/ ijms221910300

Academic Editor: Elena Giulotto

Received: 4 September 2021

Accepted: 21 September 2021

Published: 24 September 2021

Publisher's Note: MDPI stays neutral with regard to jurisdictional claims in published maps and institutional affiliations.

Copyright: (c) 2021 by the authors. Licensee MDPI, Basel, Switzerland. This article is an open access article distributed under the terms and conditions of the Creative Commons Attribution (CC BY) license (https:// creativecommons.org/licenses/by/ $4.0 /)$.

\begin{abstract}
The Ponto-Caspian region is the main donor of invasive amphipods to freshwater ecosystems, with at least 13 species successfully established in European inland waters. Dikerogammarus spp. and Pontogammarus robustoides are among the most successful, due to their strong invasive impact on local biota. However, genomic knowledge about these invaders is scarce, while phylogeography and population genetics have been based on short fragments of mitochondrial markers or nuclear microsatellites. In this study, we provide: (i) a reconstruction of six mitogenomes for four invasive gammarids (D. villosus, D. haemobaphes, D. bispinosus, and P. robustoides); (ii) a comparison between the structure of the newly obtained mitogenomes and those from the literature; (iii) SNP calling rates for individual $D$. villosus and $D$. haemobaphes from different invasion sites across Europe; and (iv) the first time-calibrated full mitogenome phylogeny reconstruction of several Ponto-Caspian taxa. We found that, in comparison to other gammarids, the mitogenomes of Ponto-Caspian species show a translocation between the tRNA-E and tRNA-R positions. Phylogenetic reconstruction using the mitogenomes identified that Ponto-Caspian gammarids form a well-supported group that originated in the Miocene. Our study supports paraphyly in the family Gammaridae. These provided mitogenomes will serve as vital genetic resources for the development of new markers for PCR-based identification methods and demographic studies.
\end{abstract}

Keywords: Amphipoda; invasive species; population genetics; mitogenome; Ponto-Caspian; SNP

\section{Introduction}

The Ponto-Caspian region (Azov, Black, and Caspian seas with surrounding areas) is a significant donor of invasive amphipods to European inland water bodies [1-3]. At least 13 morphospecies have successfully established populations to date [4,5]. Among them, Dikerogammarus villosus and Dikerogammarus haemobaphes have colonized most of the European main inland water bodies in less than 20 years, having a deteriorating effect upon local benthic communities [6-8]. Dikerogammarus bispinosus (a third invasive representative of the genus Dikerogammarus) reached the Rhine estuary via the southern invasion corridor [1]; however, populations of this species have been declining in the lower section of the Danube in recent decades $[9,10]$. Dikerogammarus villosus and D. haemobaphes earned their nicknames "killer" and "demon" shrimp, respectively, due to their impacts on 
local fauna. They are the highly adaptable, physiologically tolerant, and efficient predators characterized by a high fecundity, which allows them to dominate local macroinvertebrate communities [8,11-13], as well as introduce pathogenic species [14-19]. In particular, D. villosus is regarded as one of the worst 100 invasive species in Europe $[20,21]$ and has been deemed the worst non-native amphipod invader of English and Welsh waterways by the UK Environment Agency [22]. In recent years these species have accelerated their invasion, as new records, especially of D. villosus, were noted in English and Welsh waterways [22], Baltic States [7], and the Masurian Lake district in Poland [23]. Dikerogammarus haemobaphes has most recently invaded Boroughbridge in North Yorkshire, UK, carrying with it several invasive parasites [24]. The European invasion of D. villosus is followed by D. haemobaphes [6] and, most recently, by Pontogammarus robustoides [25,26].

Phylogeographic and population genetics data have been attained for D. villosus throughout its invaded range [27-29]. Two invasive populations, one originating from the Danube and the other originating from the Dnieper, were found in Central and Western Europe. They are genetically differentiated and allopatrically distributed, and neither of them show signs of a loss of genetic diversity compared to respective source areas. A recent phylogeographic study by [6] on D. haemobaphes revealed the presence of cryptic lineages in the native region, as well as shallow differentiation in populations from the European invaded area. The evolutionary processes behind the invasion of these species are still under examination $[6,27,28,30,31]$. Little is known about the most recent colonization of Europe by P. robustoides, including its molecular diversity [25]. It's dispersal routes and molecular divergence require exploration, since this species has the potential to be invasive [11,32].

The original descriptions of D. villosus (Sowinsky, 1894), D. haemobaphes (Eichwald, 1841), and P. robustoides (Sars, 1894) placed them in the genus Gammarus (respectively, Gammarus marinus var. villosa Sowinsky, 1894, Gammarus haemobaphes Eichwald, 1841, and Gammarus robustoides G.O. Sars, 1894) in the family Gammaridae Leach, 1814. Then, ref. [33] established the genus Dikerogammarus, to which he moved D. villosus and D. haemobaphes, joined later by D. bispinosus Martynov, 1925. In 1904, ref. [34] established the genus Pontogammarus into which P. robustoides was placed. Moreover, ref. [35], based on several morphological features shared by Ponto-Caspian species, challenged the former genuslevel classification within Gammaridae, and placed Dikerogammarus together with several newly established genera into an informal taxonomic group he called "Dikerogammarus-Pontogammarus complex" or "Ponto-Caspian complex of genera". Following this, ref. [36], after re-evaluation of the morphological traits within the group, moved the whole "Dikerogammarus-Pontogammarus complex" to the family Pontogammaridae Bousfield in 1977.

Several decades later, ref. [37] conducted a general taxonomic revision of Amphipoda based on a cladistic analysis of a number of morphological traits, which excluded Dikerogammarus from the Pontogammaridae and placed it back into the Gammaridae. More recently, molecular studies by [38,39] suggested high phylogenetic affinity of Dikerogammarus to other genera of the former "Dikerogammarus-Pontogammarus complex" (sensu [35]) that are classified within Pontogammaridae. Nevertheless, given the limited number of molecular markers used and the lack of resolution in the phylogenetic tree, the exact relationships within as well as between the pontogammarid clade and other gammarids were not fully identified. The abovementioned authors continued to refer to them as "Ponto-Caspian gammarids" or "Ponto-Caspian group of genera", without a conclusion into which family they should belong. Further, the within-genus taxonomy of Dikerogammarus continues to be a subject of discussion and is far from being fully resolved, mainly due to poor descriptions of some species, as well as missing type materials. For example, until recently, D. bispinosus was considered a subspecies of or synonym for D. villosus Sowinsky 1894, while D. villosus was considered as a synonym for D. haemobaphes Eichwald 1841 [40]. A molecular study by [31] resolved this question and confirmed the taxonomic status of D. villosus, D. haemobaphes, and D. bispinosus as three separate species. Nevertheless, 
the most recent studies show that, while $D$. villosus seems to be a well-defined species over its geographic range [27], both D. haemobaphes and D. bispinosus contain divergent phylogenetic lineages, which may represent yet undescribed, cryptic, or pseudocryptic species $[6,41]$.

There is still relatively scarce knowledge on the genomics of the Amphipoda. To date, five amphipod (complete or partial) genomes are available for the species: Orchestia grillus, Trinorchestia longiramus, Gammarus roeselii, Hyalella azteca, and Parhyale hawaiensis [42]. The main obstacle to progression is their large and repetitive genome. Thus far, only two such genomes have been completed, first for Parhyale hawaiensis with a size reaching $3.6 \mathrm{~Gb}$ [43] and second for Gammarus roeselii with a size estimated at $3.4 \mathrm{~Gb}$ [44], both being among the largest reported arthropod genomes [43]. Another potential problem could be polyploidization, which was documented for the Ohrid Lake Gammarus species flock [45]. Genetic data have also been gathered via a transcriptomic approach, providing nuclear and mitochondrial data for $\sim 40$ species of amphipod [46-49].

In the absence of genomic data, mitochondrial genomes are much easier to sequence and reconstruct and are often used in phylogenetic models [50-52]. The structure of the amphipod mitochondrial genome resembles the general structure of other animal mitogenomes; being small (14-18 kb) circular molecules and having 37 genes: 13 protein coding, 2 rRNA, and 22 tRNA [53]. Due to their small size and relative abundance, the complete mitogenome sequences are relatively easy to obtain from next generation sequencing projects [43,54-57], as well as for the widely distributed freshwater Palearctic superfamily, Gammaroidea [50-52,58]. It is common for an important resource, mitochondrial transcripts, to not be assembled and published, despite the fact that a large number of reads in each data set belong to the mitochondrial genome [59].

Pertinent to the Dikerogammarus spp., ref. [55] published the first mitochondrial genome for a single D. haemobaphes from an invasive population in England, which became the first reported full mitogenome for the family Pontogammaridae. Moreover, ref. [55] reported a potential recombination and duplication of a tRNA, as well as a putative duplication of an ATP8-like gene within the control region (CR). The primary goal of our study is to provide a comparative reconstruction of mitogenomes of four invasive gammarids of Pontio-Caspian origin (D. villosus, D. haemobaphes, D. bispinosus, and P. robustoides). Second, we will compare the structure of the obtained mitogenomes to those of the other gammarids available in public databases to search for putative rearrangements. Third, we will compare mitochondrial polymorphisms between individual $D$. villosus and D. haemobaphes that represent different invasive populations in Europe and, in the case of D. villosus, the native Ponto-Caspian population. Finally, we will provide the first time-calibrated reconstruction of the phylogenetic position of these Ponto-Caspian taxa vs. other gammaroids using mitochondrial genes.

\section{Results}

\subsection{Molecular Species Identification}

The COXI barcoding prior to sequencing supported morphological identification of the studied Ponto-Caspian species. After using BLAST on all new assemblies based on GenBank data, and precise identification through COXI and 16S genes, there was a complete agreement most of the time. In two cases, the BLAST search of the assemblies showed misidentifications with a 100\% fragment identity (Table S1). The first case was Pandorites podoceroides (SRR3467097), which was revealed to be Obesogammarus crassus (the name used throughout the text). The second case was the transcriptome of Gammarus pulex (SRR8089725), which in fact showed the presence of two mitochondrial genomes, one of G. fossarum and second belonging to G. pulex; only the latter was used in our analyses.

\subsection{Structure}

The three mitogenomes constructed for $D$. villosus consisted of $15,173 \mathrm{bp}$ to $15,176 \mathrm{bp}$ circular sequences in length. The mitogenome for D. bispinosus reached a length of $15,366 \mathrm{bp}$ 
and the newly assembled mitogenome for $D$. haemobaphes (Germany) constituted 15,468 bp. For partial reconstruction of $P$. robustoides mitogenome, we were able to obtain a single linear contig, 14,339 bp long. The 37 expected genes (Figure 1) were annotated and resembled the canonical bilaterian gene set: 13 protein-coding genes, 2 rRNA genes, and 22 tRNA genes. Gene order and position for all Ponto-Caspian mitogenomes as well as for Obesogammarus crassus and Homoeogammarus veneris (Gammaridae), are the same (Figure 2). Relative positions of all protein and rRNA coding genes follow the Pancrustacea ground pattern, but the position and transcriptional polarity of some tRNA coding genes, in a few cases, are different (Figure 2). A single rearrangement is observed for tRNA genes relative to the pattern observed for Gammarus spp., i.e., the tRNA-E and tRNA-R switched places in the Ponto-Caspian amphipods (Dikerogammarus spp., O. crassus) and in H. veneris. Since the sequences reconstructed from transcriptomic data have inherently poor coverage for tRNA expression (Figure S1), the data for some of the Ponto-Caspian sister lineages must be interpreted cautiously.

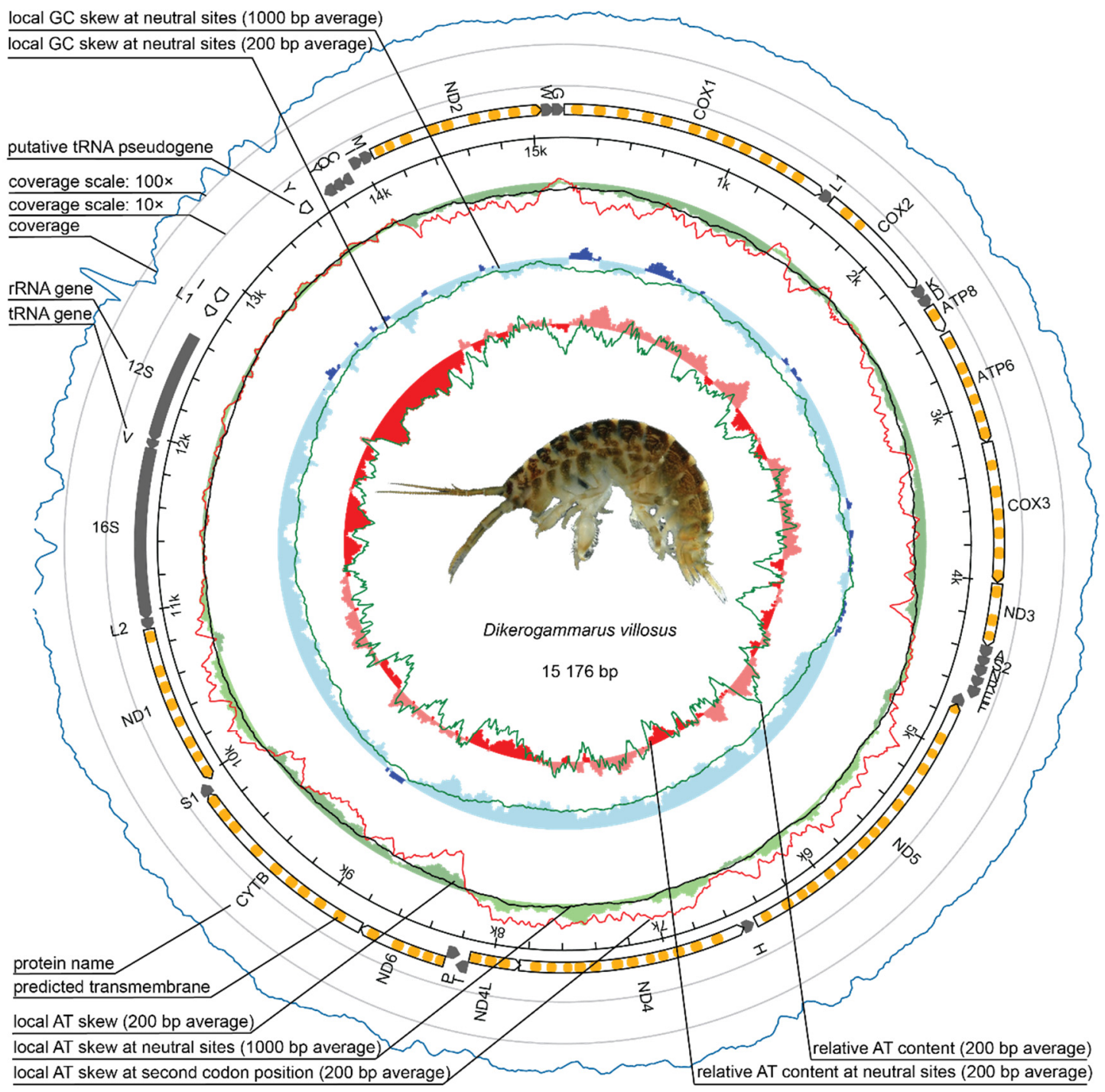

Figure 1. Genetic map of the mitochondrial genome for the invasive Ponto-Caspian amphipod, Dikerogammrus villosus. The mitogenome was generated using the mitoconstrictor set of tools. Transfer RNA genes are labelled by their single-letter amino acid code (photo. of D. villosus by M. Grabowski). 

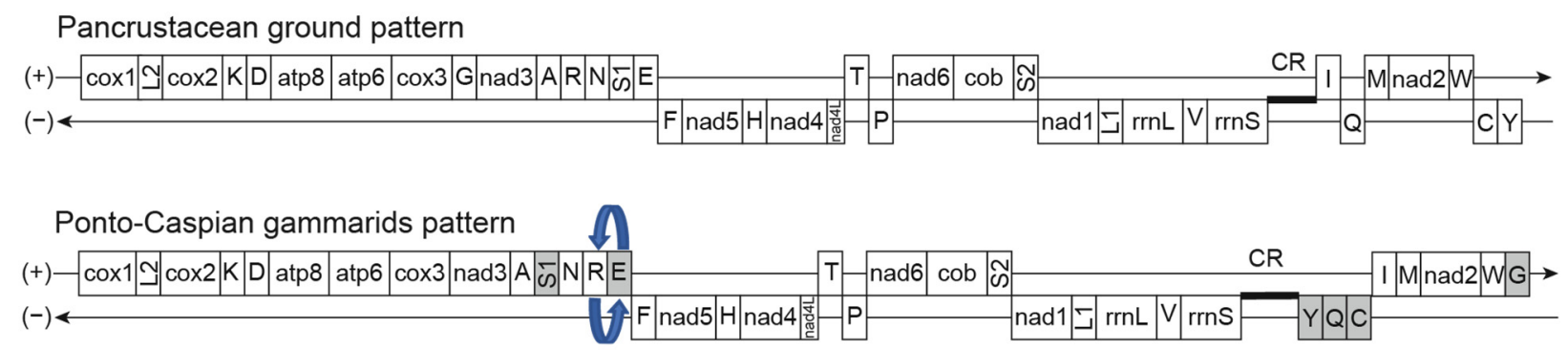

Gammarus sp. general pattern

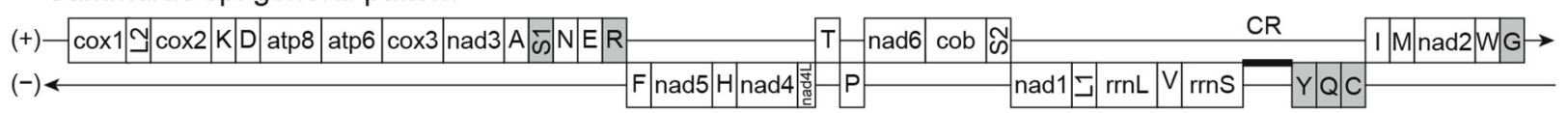

Figure 2. Organization of mitochondrial genomes in the Ponto-Caspian gammarids in comparison with the pancrustacean ground pattern and representative Gammarus genera. Gene features with altered location relative to the pancrustacean ground pattern are shown in a grey colour. Rearrangement of a tRNA is shown using blue arrows. A ' + ' indicates the forward DNA strand and '-' indicates the reverse DNA strand. Transfer RNA genes are labelled by their single-letter amino acid code. The figure follows the convention proposed in [50].

The mitogenomes have a GC content of $32.2 \%$ for D. villosus; $34 \%$ for D. haemobaphes; $30.6 \%$ for D. bispinous; and $32.2 \%$ in partial P. robustoides mtDNA. Rich AT composition is visible in the control region (Figure 1), which is also characterized by the presence of a poly-T stretch and some tandemly repeated sequences.

\subsection{SNP Recovery}

The comparison of reads from different ranges allowed us to identify several polymorphic sites across the mitogenome of both D. villosus and D. haemobaphes (Table S2). In total, 32 polymorphic sites differentiate D. villosus from Turkey and Poland, while 21 polymorphic sites differentiate between individuals from Poland and England. The D. haemobaphes from Germany differs from those collected in the UK by 52 polymorphic sites. All the polymorphic sites with the information on reading coverage, variant frequency, and variant $p$-value are provided in Table S2. The polymorphic sites within genes, their position, and their impact on translation are provided in Table S2. For all analysed species, the highest number of polymorphic sites is in ND5 and ND4 (4 to 7 SNPs). Equally, these are the longest genes (ND5: 1729 bp, ND4 1312 bp), except for COXI (1515-1535 bp); however, the COXI gene only has $2-3 \mathrm{SNP}$ 's recorded (Table S2).

\subsection{Phylogeny Reconstruction}

The reconstructed phylogenetic trees share topology, showing the same well-supported clades (Figures 3, S2 and S3). For the maximum likelihood reconstruction, the protein-based tree gave a slightly higher support than the reconstruction based on mtDNA sequences. The Bayesian time-calibrated phylogeny reconstruction provided high posterior probabilities for most of the nodes (Figures 3 and S3).

According to this phylogeny, the superfamily Gammaroidea includes a few wellsupported clades that diverge in the early/middle Eocene (Figures 3 and S3). First, the Baikalian families, Crypturopodidae and Micruropodidae, form a well-supported clade that has a sister relationship with a clade containing all of the other representatives of the superfamily Gammaroidea included in our analysis. The latter is composed of two clades, whose phylogenetic relationships point to paraphyly of the family Gammaridae. One includes E. berilloni, E. marinus, H. veneris (Gammaridae), and the Ponto-Caspian genera i.e., Dikerogammarus (Gammaridae), Pontogammarus (Pontogammaridae), and Obesogammarus (Pontogammaridae). This clade already started to diverge in the middle Eocene, when the E. berilloni lineage branched off, followed by the E. marinus lineage in the late Eocene. Homoeogammarus veneris is a sister lineage to the Ponto-Caspian genera, from which it 
diverged in the mid-Oligocene. The latter diverged in the middle Miocene. The three Dikerogammarus species diverge at the mid-to-late Miocene and form a monophyletic clade relative to $P$. robustoides and $O$. crassus.

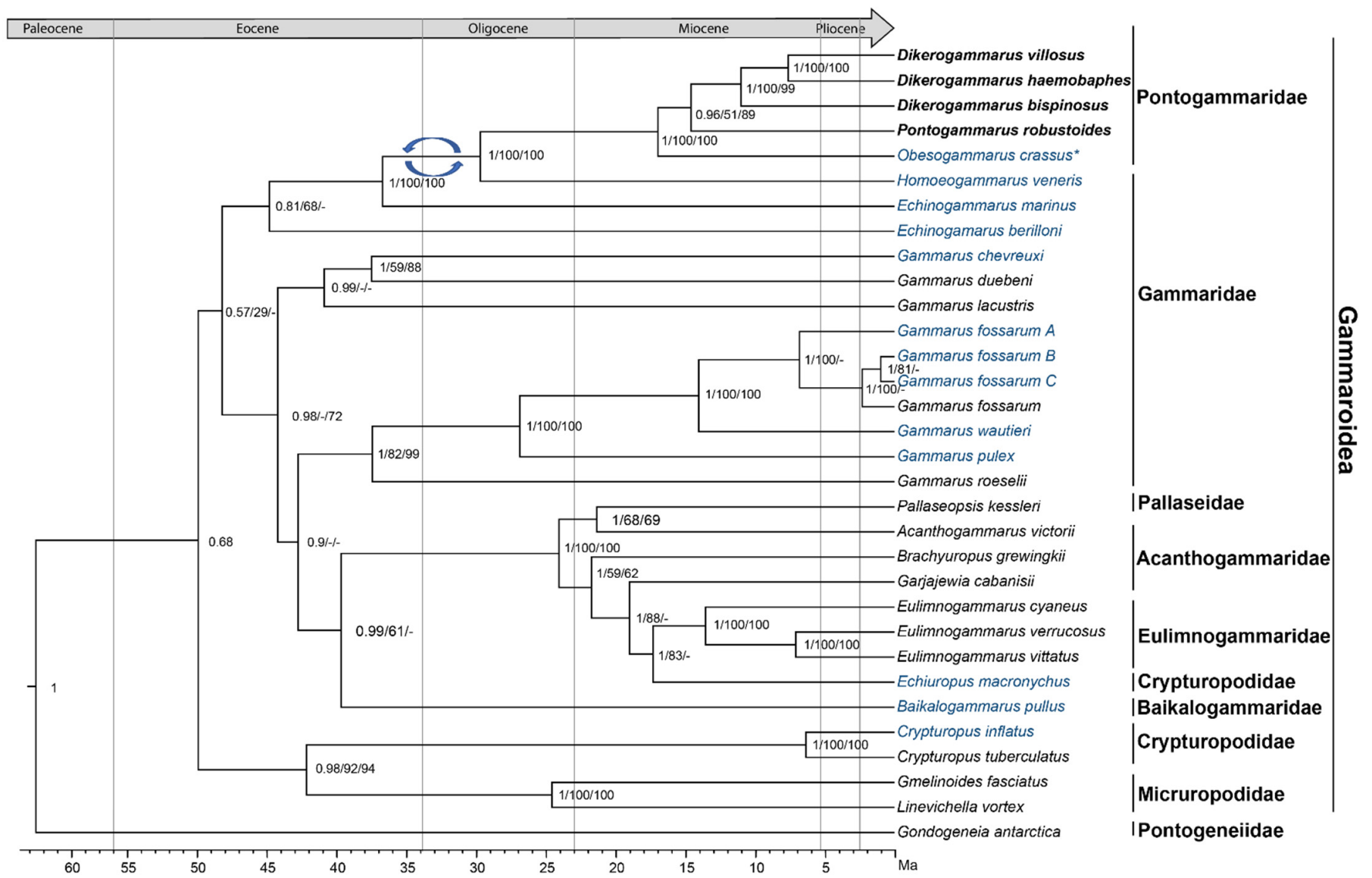

Figure 3. A Bayesian phylogenetic maximum clade credibility chronogram of the Gammaroidea, based on available mitogenomic and mitochondrial transcriptome data. The sources of sequences used are indicated in Table S1. Numbers next to branches indicate support: Bayesian posterior probabilities from chronogram/bootstrap values from maximum likelihood (ML) phylogeny on full data/bootstrap value for ML based on proteins (see Materials and Methods). Arrows indicate a putative tRNA rearrangement. On the right, the vertical lines indicate the families and the superfamily. Species names in bold sequences indicate assembled de novo from own data, names in blue indicate newly reconstructed from third party transcriptomic data. *indicates Pandorites podoceroides (SRR3467097), which was revealed to be Obesogammarus crassus.

The second clade includes all of the Gammarus species (Gammaridae), plus the predominantly Baikalian Pallaseidae, the endemic Baikalian Acanthogammaridae and Eulimnogammaridae, as well as the Baikalian Echiuropus macronychus. However, this species is classified in the Crypturopodidae and is instead affiliated with the Eulimnogammaridae in our analysis. Interestingly, Gammarus sp. seems to be a polyphyletic genus provided that a set of highly divergent brackish water/freshwater species (G. chevreuxi, G. duebeni, G. lacustris) form a sister clade to one containing freshwater Gammarus sp. (G. roeselii, G. fossarum, G. wautieri, G. pulex) and the Baikalian taxa. All of the above divergences may be dated to the middle and late Eocene. Finally, the Gammarus lineages seem to start their diversification already in the late Eocene, while the diversification of the Baikalian taxa dates back to the late Oligocene/early Miocene.

\subsection{Substitution Rates}

The mean relative substitution rate for the superfamily Gammaroidea falls within a range of 0.0150 to 0.0213 substitutions $\times \mathrm{My}^{-1}$, being similar to the pre-established COXI 
rate of 0.01773 . The substitution rate of the relatively short ATP-8 gene has a value of 0.0258 (Figure 4). All of the statistics for the protein-coding gene substitution rates are provided in Table S3.

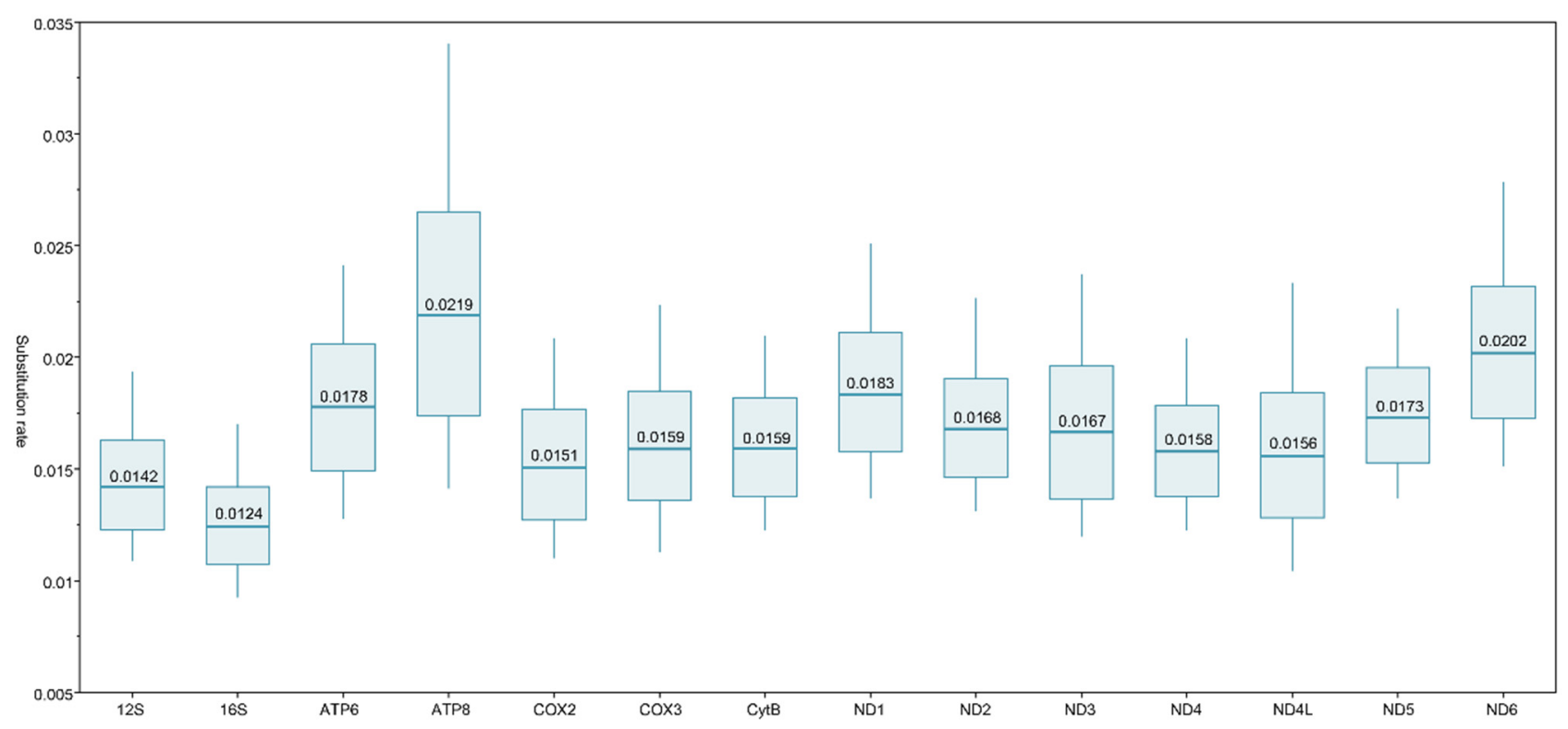

Figure 4. Substitution rates for 12 protein-coding and 2 rRNA mitochondrial genes. The mean value is provided within the boxplot (substitution per site $\times \mathrm{My}^{-1}$ ), whiskers stand for value range, box stand for SD.

\section{Discussion}

Gammarids of Ponto-Caspian origin are the most prominent colonizers of European inland water bodies [4]. In most cases, they are considered to be invaders, and a significant threat to native biodiversity $[8,60]$. The mitogenomic diversity data collected in this study provide information regarding the resolution of their taxonomic affinities [39] and presents a foundation for further genetic tool development to benefit their identification, colonization route(s), and population dynamics. The accumulation of mitogenomic data for the group is progressing [55]; however, it is important to stress that all genomic resources, prior to incorporating in analyses, should be properly validated. For superfamily Gammaroidea we have detected two cases of species misidentification.

After inspecting the assemblies based on transcriptome sequences for G. pulex provided by [48], it appears that the reads belong to two species, G. pulex and G. fossarum. COXI barcoding fragments allow us to identify G. fossarum as belonging to BIN: BOLD:ACG7784a widely distributed species in France and Germany [61]. Both species are morphologically similar and may be hard to distinguish. The mitogenome assembled from the G. fossarum reads, mislabeled as G. pulex, was used in studies by [50,51]. The second misidentification detected in our study relates to Pandorites podoceroides, whose mtDNA fits with $O$. crassus from the Ponto-Caspian region; both species belong to Pontogammaridae. These mislabeled data have been used by [49]. Both mentioned misidentification, which could be avoided through simple barcoding to verify morphological determination. These findings support the need for a proper DNA barcode reference library for all organisms. Such misidentifications may result in avoidable consequences, as more countries and stakeholders include metabarcoding as a standard biomonitoring protocol [62-64].

In this case, G. pulex and G. fossarum have wide European ranges and are both often viewed as bioindicators [65] and model organisms for ecotoxicological studies [66]. Contrary to this, proper morphological discrimination of both species is not trivial, and we can find cryptic (possibly hyper-cryptic) diversity when using molecular studies [61,67,68]. Moreover, correct species identification is crucial when studying gene expression, especially 
when discrepancies of certain expression patterns may be the result of species-specific factors and not of an experimental factor or stressor.

The mitochondrial genomes of Ponto-Caspian gammarids reveal a conservative order of genes and transcriptional polarity similar to the pancrustacean ground pattern [69]. Changes in the position and location of tRNA polarity have already been shown in mitogenome reconstructions for representatives of other gammarids $[50,51,58]$. The outstanding feature, for the Ponto-Caspian amphipods and their sister Homoeogammarus in comparison to other species from the superfamily Gammaroidea, is a switch of position of two tRNA (E and R). This rearrangement was first observed for D. haemobaphes [55]. However, analysis and gene annotation conducted via our pipeline cannot unequivocally confirm a non-similar duplication of the ATP8, or duplication of tRNA Q genes in the structure of D. haemobaphes or other Ponto-Caspian gammarids [55]. It is possible that these duplications were a result of software errors, likely at the assembly or annotation step(s), which may be avoided with longer read sequencing or follow-up PCR validation in future studies. However, duplications are not rare in the amphipod mitogenome. A duplication of the control region in some Gammaridae was putatively identified in the Baikalian Garjajewia cabanisii [52], and also reported for the mitogenome of G. roeselii [50]. The mitogenomes of the Ponto-Caspian species that we have sequenced do not show such structures. However, in our case, the coverage of the control region is lower than in the study of [50], and is rather problematic for assembly due to high AT content and putative repetitions.

To date, studies using amphipod mitochondrial DNA focus primarily on phylogeographic and population dynamics, including only fragments of COXI and 16S genes [6,70]. In our study, we detected multiple SNPs across most of the mitochondrial genes for different populations, both for $D$. villosus and D. haemobaphes. Detection of SNPs at the species level can be valuable to the study of invasive organisms, helping one to identify their source population(s) and determine their invasion corridor(s) [71-73]. Growing accessibility, together with falling prices of high-throughput sequencing, will undoubtedly make multigene SNP data a primary resource to study biological invasions [74]. This can be achieved using RNA-Seq data, which are particularly rich in mitochondrial transcripts.

Our phylogenetic analysis reveals well-supported relationships between four members of the Pontogammaridae using mitogenomics. The results show that the Pontogammaridae includes a supported monophyletic clade with close affinities to Homeogammarus, which supports the results of [38]. Our observation that Echinogammarus is a sister genus to the aforementioned taxa is also supported by nuclear data from other studies [39]. As such, ref. [38] suggest moving E. marinus to the genus Marinogammarus, originally created for that species by [75]. Given that E. marinus is the type species for Marinogammarus, our results support such a claim. The type species of Echinogammarus is E. berilloni, present in our analysis and clearly belonging to another lineage. The monophyletic clade composed of Pontogammaridae and Echinogammarus (Gammaridae) was also shown by [50] using a concatenated dataset of mitochondrial coding genes; however, in their study, this group was a sister lineage to all other families of the superfamily Gammaroidea. Our study, utilizing all mitochondrial genes with separate partitions, suggests a more complex pattern of Gammaridae evolution, including clades formed by Baikalian Micruropodidae and Crypturopodidae as sister groups to all other families. This deeper structure remains unresolved, even when using whole transcriptome data [49]. The paraphyly of the Gammaridae is confirmed in our study; however, this is not the same as in the study by [50], with Baikalian families as well as the Pontogammaridae. These results support complex and ancient origins of the family Gammaridae, and they are further supported by studies using nuclear data $[38,39]$. Our study, among others, highlights that the whole superfamily requires taxonomical revision using integrative methods.

Our results suggest that the Eocene could be a backdrop for the burst of diversification observed for the Gammaroidea, resulting in the diversity of families existing today. This early time frame of their speciation is supported by previous studies based on nuclear and 
mitochondrial sequence data [38]. Interestingly, the diversification of the Pontogammaridae, at least according to our study, takes place between ca. 17 and $8 \mathrm{Ma}$, and coincides with the time scale of their earliest recorded potential representative, whose fossil record resides in the Upper Sarmatian (ca. 9 Ma: [76,77]).

\section{Materials and Methods}

\subsection{Material Collection and DNA Isolation}

Dikerogammarus villosus was collected from its invasive ranges in Poland (50.412 N, $18.108 \mathrm{E}$, April 2009, $n=2)$, England (52.3024 N, $0.3208 \mathrm{~W}$, September 2016, $n=2)$, and its native range in Turkey (41.316 N, 28.620 E, September 2007, $n=1)$. Dikerogammarus haemobaphes was collected in Germany $(47.973 \mathrm{~N}, 11.352 \mathrm{E}$, May 2011, $n=1)$. Dikerogammarus bispinosus was collected in Hungary (47.518 N, $19.042 \mathrm{E}$, April 2012, $n=1)$. Material was collected using a standard benthic hand-net and identified using available keys (i.e., [78]). The voucher specimens and isolated DNA are stored at the Department of Invertebrate Zoology and Hydrobiology, University of Lodz. Material from England is stored at the Centre for Environment, Fisheries and Aquaculture Science (Cefas) repository. DNA isolation for all specimens followed a standard phenol-chloroform protocol according to a procedure from [79]. To confirm the species identification, the COXI (cytochrome c oxidase subunit 1) fragment was amplified and sequenced, following a procedure from [27]. The COX1 sequences were used in BLAST searches to confirm morphological identification.

\subsection{Sequencing/Assembly}

Isolates with confirmed species identification were tested for DNA quality and quantity using Qubit (Qubit dsDNA BR Assay, ThermoFisher scientific, Waltham, MA USA) and Nanodrop machines. Libraries were prepared from $1 \mathrm{ng}$ of whole genomic DNA using the Nextera XT preparation kit (Illumina) twice with $150 \mathrm{bp}$ paired-end sequencing on an Illumina NextSeq500 sequencer (Illumina, San Diego, CA, USA) in the Biobank Lab, Department of Molecular Biophysics, University of Lodz.

The quality of the reads before and after the pre-processing steps were assessed using FastQC (v0.11.5) [80]. Quality trimming and removal of remaining sequencing adapters was performed with Trimmomatic [81]. Mitobim [82] and NOVOplasty [83] were used to pull out and assemble any mitochondrial genomes from raw DNA reads. The assemblies were then verified through mapping of mitochondrial reads using Bowtie2 [84]. Annotation and visualization were performed using a mitoconstrictor set of tools [85].

In order to provide an extensive set of outgroups within the Gammaroidea superfamily, available databases were also searched, and data downloaded. The mitochondrial genes were obtained from annotated mitochondrial genomes available through NCBI (GenBank). Additionally, unannotated raw transcriptome data (NCBI SRA) were downloaded and assembled anew. A list of species and accession codes of new assemblies and read data are provided in Table S1. The same approach was used to obtain mitogenomic sequences from downloaded SRA data as described above, but the de novo assembly was conducted using Trinity [86] and an identification of the mitochondrial sequences was completed with wise2 [87] and infernal [88] using scripts from the mitoconstrictor pipeline. The mitochondrial sequences were then validated through a realignment of the filtered reads. Mitochondrial contigs were further assembled in CLC genomic workbench (QIAGEN, Redwood City, CA, USA) and verified by mapping the raw reads at the final, single mitochondrial contig.

Final annotation was performed using a mitoconstrictor set of tools. The reconstructed mitochondrial COX1 genes (for both: downloaded and own data) and, when available, rRNA genes, were tested with blast vs. GenBank and our own unpublished database to ensure proper species identification of the data. 


\subsection{SNP Recovery}

To identify variation between specimens from each of the studied ranges, we performed SNP recovery. All reads per individual were mapped to the reference mitogenome using Bowtie2 [89]. In the case of D. villosus, the newly assembled mitogenome from Poland was used as the reference and the reads from native range (Turkey) and invasive range (England) were used for mapping. For D. haemobaphes, the already published mitogenome from England (MK644228) was used as a reference and the reads from the newly assembled mitogenome of $D$. haemobaphes from Germany were mapped. For the identification of the SNPs, we used the "Find Variations/SNPs" tool through Geneious 11.1 software [90]. The initial minimum variant frequency was set to 0.35 , the $p$-value was calculated using an approximate method, the maximum variant $p$-value was set to $10^{-6}$ and the minimum strand $p$-value to $10^{-5}$. The variants were called from both coding and noncoding regions, except for the AT-rich control region.

\subsection{Phylogenetic Analysis with Molecular Clock Calibration}

To analyze the diversification of the Ponto-Caspian gammarids across both a phylogenetic and a temporal context, we reconstructed the amphipod phylogeny using a molecular clock approach. A set of 28 species with available mitogenome data from the superfamily Gammaroidea was used. Gondogeneia antarctica (Pontogeneiidae) was added as an outgroup (Table S1). The dataset included 13 protein-coding genes and $2 \mathrm{rRNA}$ genes. The coding genes were aligned via MAFFT [91] with automatic determination of algorithm and gap open penalty set to 2.5 , while rRNA were aligned using structural aligner software LocARNA [92]. The alignments were inspected by eye to identify possible misalignments of triplets. In the case of coding genes, they were trimmed to codon positions and, in all cases, trimmed when individual sequences were longer relative to the others, or due to putative miss-annotations (e.g., 12S gene of G. fossarum-KY197961). Missing positions at the ends of the sequences were coded with unknown nucleotides to exclude them from the phylogenetic analyses. The whole set of genes reached a length of 12,862 bp.

The phylogeny was reconstructed using Bayesian inference in BEAST 2.6.2 [93]. The evolutionary rates for gammarids, especially for COX1, have been vastly studied and cross-validated using both fossil and geological data (e.g., [94-96]), allowing us to apply the general rate of 0.01773 [76] for the COXI gene. Four partitions were used: ND6, having a different substitution model, was treated as a separate partition; 11 protein-coding genes were concatenated in one partition; $12 \mathrm{~S}$ and $16 \mathrm{~S}$ rDNA genes with the same substitution model were also treated as one partition, as well as COX1 as a calibrated partition. The substitution model was selected via bModelTest [97]. A birth-death tree model and relaxed clock were set as priors. Four runs of the MCMC, each 50 million generations long and sampled every 5000 generations, were performed and examined for convergence in TRACER 1.7 [98]. All parameters in each run reached the effective sample size (ESS) above 200 and were combined using LogCombiner2.6.2 [93]. The final tree was summarized with TreeAnnotator 2.6.2 [93].

To provide relative rates of evolution for each of the protein-coding genes, the above analysis was also run using all genes as separate partitions. The difference in settings for the clock, in this case a simple "strict clock", was used for each partition and the length of MCMC was set to 100 million generations.

To provide additional support for the BI topology, we also reconstructed a phylogeny using the maximum likelihood approach through RAxML 8.2.8 [99]. For this analysis, all 15 genes were concatenated. The best-scoring ML tree was produced using the GTR + $\mathrm{I}+\mathrm{G}$ substitution model. Bipartition information was drawn from phylogeny obtained with the rapid hill-climbing tree search algorithm. Statistical support was estimated with a thorough bootstrap test set to 1000 repetitions. To limit the impact on the phylogeny of highly divergent 3rd codon position, the phylogeny was reconstructed using amino acid sequences. All protein-coding sequences were translated, realigned in MAFFT using 
BLOSUM65 [91] scoring matrix automatic selection of algorithm, and then concatenated. The tree was reconstructed in RAxML 8.2.8 using the same settings as above.

\section{Conclusions}

We present the first full de novo mitochondrial genomes of D. villosus and D. bispinosus, as well as a new assembly for $D$. haemobaphes and a partial mitochondrial genome for $P$. robustoides. These mitogenomes serve as a vital resource for the development of new genetic markers for PCR-based identification methods, as well as SNP-based demographic studies. The reconstruction of these mitogenomes shows that Ponto-Caspian gammarids, and their sister lineage Homoeogammarus, show a stable structural feature that involves the tRNA-E and tRNA-R being switched in place relative to other gammarids. Aside from this, the pancrustacean structural format is adhered to.

The phylogenetic reconstruction we provide for Dikerogammarus spp. and P. robustoides, based on the mitogenomes of Ponto-Caspian gammarids and other Gammaroidea, reveals a well-supported group that appears to have originated in the Miocene. Our study supports paraphyly in the Gammaridae family, advocating the need for detailed integrative taxonomic revision of the Gammaroidea superfamily.

Supplementary Materials: The following are available online at https:/ /www.mdpi.com/article/10 .3390/ijms221910300/s1.

Author Contributions: Conceptualization, T.M. and A.B. with contribution of M.G. and T.R.; methodology, T.M. and A.B.; formal analysis, A.B. and T.M.; resources, D.S., T.M., A.B.; data curation, T.M. and A.B.; writing—original draft preparation, T.M.; writing—review and editing, T.M., M.G., T.R., J.B., A.B., D.S.; visualization, T.M. and A.B.; funding acquisition, D.S., T.R., T.M., J.B. All authors have read and agreed to the published version of the manuscript.

Funding: The study was partially funded by National Science Centre projects: 2018/31/D/NZ8/03061; 2017/01/X/NZ8/01086 and partially by the statutory funds of the Department of Invertebrate Zoology and Hydrobiology, University of Lodz. Tomasz Rewicz and Tomasz Mamos were supported by the Scholarship of the Polish National Agency for Academic Exchange (NAWA) at the Bekker Programme (T.M. project nb. PPN/BEK/2018/1/00225, T.R. project nb. PPN/BEK/2018/1/00162). J.B. would like to thank NERC funding (\#1368300) involved in the collection of $D$. haemobaphes data and personal funds at the University of Florida (USA) and Teesside University (UK) for further sequencing and analysis.

Institutional Review Board Statement: Not applicable.

Informed Consent Statement: Not applicable.

Data Availability Statement: New mitochondrial genomes obtained for Ponto-Caspian amphipods are available in GenBank under accession numbers: D. villosus: OK173836-OK173838, D. haemobaphes: OK173839, D. bispinosus: OK173840, P. robustoides: OK173841. Nucleotide sequence of newly obtained assemblies based on GenBank data are available in the Third Party Annotation Section of the DDBJ/ENA/GenBank databases under the accession numbers TPA: BK059223-BK059235 (details in Table S1).

Acknowledgments: Authors would like to thank Jan-Niklas Macher for consultation and sharing of datasets at an early stage of work, Paulina Borówka for initiating contacts between Dept. of Invert. Zoology and Hydrobiology UniLodz with Biobank UniLodz, and Alicja Konopacka for her tireless work on morphological material identification. Computer-intensive tasks were run on PL-GRID infrastructure and sciCORE (https:/ / scicore.unibas.ch (accessed July-September 2020)) scientific computing center of the University of Basel.

Conflicts of Interest: The authors declare no conflict of interest.

\section{References}

1. Bij de Vaate, A.; Jazdzewski, K.; Ketelaars, H.A.M.; Gollasch, S.; Van der Velde, G. Geographical patterns in range extension of Ponto-Caspian macroinvertebrate species in Europe. Can. J. Fish. Aquat. Sci. 2002, 59, 1159-1174. [CrossRef] 
2. Copilaș-Ciocianu, D.; Sidorov, D. Taxonomic, ecological and morphological diversity of Ponto-Caspian gammaridean amphipods: A review. bioRxiv 2021. [CrossRef]

3. Leuven, R.S.E.W.; van der Velde, G.; Baijens, I.; Snijders, J.; van der Zwart, C.; Lenders, H.J.R.; de Vaate, A.B. The river Rhine: A global highway for dispersal of aquatic invasive species. Biol. Invasions 2009, 11, 1989-2008. [CrossRef]

4. Copilaș-Ciocianu, D.; Sidorov, D.; Šidagytè-Copilas, E. Global distribution and diversity of alien Ponto-Caspian amphipods. bioRxiv 2021. [CrossRef]

5. Holdich, D.M.; Pöckl, M. Invasive crustaceans in European inland waters. In Biological Invaders in Inland Waters: Profiles, Distribution and Threats; Gherardi, F., Ed.; Springer: Berlin, Germany, 2007; pp. 29-75.

6. Jażdżewska, A.M.; Rewicz, T.; Mamos, T.; Wattier, R.; Bącela-Spychalska, K.; Grabowski, M. Cryptic diversity and mtDNA phylogeography of the invasive demon shrimp, Dikerogammarus haemobaphes (Eichwald, 1841), in Europe. NeoBiota 2020, 57, 53. [CrossRef]

7. Minchin, J.D.; Arbačiauskas, K.; Daunys, D.; Ezhova, E.; Grudule, N.; Kotta, J.; Molchanova, N.; Olenin, S.; Višinskienė, G.; Strake, S. Rapid expansion and facilitating factors of the Ponto-Caspian invader Dikerogammarus villosus within the eastern Baltic Sea. Aquat. Invasions 2019, 14, 165-181. [CrossRef]

8. Rewicz, T.; Grabowski, M.; MacNeil, C.; Bacela-Spychalska, K. The profile of a 'perfect' invader-The case of killer shrimp, Dikerogammarus villosus. Aquat. Invasions 2014, 9, 267-288. [CrossRef]

9. Borza, P.; Csányi, B.; Huber, T.; Leitner, P.; Paunović, M.; Remund, N.; Szekeres, J.; Wolfram, G. Longitudinal distributional patterns of Peracarida (Crustacea, Malacostraca) in the River Danube. Fundam. Appl. Limnol. 2015, 187, 113-126. [CrossRef]

10. Borza, P.; Huber, T.; Leitner, P.; Remund, N.; Graf, W. Current velocity shapes co-existence patterns among invasive Dikerogammarus species. Freshw. Biol. 2017, 62, 317-328. [CrossRef]

11. Bacela-Spychalska, K.; van der Velde, G. There is more than one 'killer shrimp': Trophic positions and predatory abilities of invasive amphipods of Ponto-Caspian origin. Freshw. Biol. 2013, 58, 730-741. [CrossRef]

12. Constable, D.; Birkby, N.J. The impact of the invasive amphipod Dikerogammarus haemobaphes on leaf litter processing in UK rivers. Aquat. Ecol. 2016, 50, 273-281. [CrossRef]

13. Grabowski, M.; Bacela, K.; Konopacka, A. How to be an invasive gammarid (Amphipoda: Gammaroidea)-comparison of life history traits. Hydrobiologia 2007, 590, 75-84. [CrossRef]

14. Bojko, J.; Stebbing, P.; Bateman, K.; Meatyard, J.; Bacela-Spychalska, K.; Dunn, A.; Stentiford, G. Baseline histopathological survey of a recently invading island population of 'killer shrimp', Dikerogammarus villosus. Dis. Aquat. Org. 2013, 106, 241-253. [CrossRef] [PubMed]

15. Bojko, J.; Dunn, A.M.; Stebbing, P.D.; Ross, S.H.; Kerr, R.C.; Stentiford, G.D. Cucumispora ornata n. sp. (Fungi: Microsporidia) infecting invasive 'demon shrimp' (Dikerogammarus haemobaphes) in the United Kingdom. J. Invertebr. Pathol. 2015, 128, 22-30. [CrossRef]

16. Bacela-Spychalska, K.; Wattier, R.A.; Genton, C.; Rigaud, T. Microsporidian disease of the invasive amphipod Dikerogammarus villosus and the potential for its transfer to local invertebrate fauna. Biol. Invasions 2012, 14, 1831-1842. [CrossRef]

17. Subramaniam, K.; Behringer, D.C.; Bojko, J.; Yutin, N.; Clark, A.S.; Bateman, K.S.; van Aerle, R.; Bass, D.; Kerr, R.C.; Koonin, E.V. A new family of DNA viruses causing disease in crustaceans from diverse aquatic biomes. mBio 2020, 11, e02938-19. [CrossRef] [PubMed]

18. Allain, T.W.; Stentiford, G.D.; Bass, D.; Behringer, D.C.; Bojko, J. A novel nudivirus infecting the invasive demon shrimp Dikerogammarus haemobaphes (Amphipoda). Sci. Rep. 2020, 10, 14816. [CrossRef] [PubMed]

19. Bojko, J.; Stentiford, G.D.; Stebbing, P.D.; Hassall, C.; Deacon, A.; Cargill, B.; Pile, B.; Dunn, A.M. Pathogens of Dikerogammarus haemobaphes regulate host activity and survival, but also threaten native amphipod populations in the UK. Dis. Aquat. Org. 2019, 136, 63-78. [CrossRef] [PubMed]

20. Vilà, M.; Basnou, C.; Gollasch, S.; Josefsson, M.; Pergl, J.; Scalera, R. One hundred of the most invasive alien species in Europe. In Handbook of Alien Species in Europe; Springer: Dordrecht, The Netherlands, 2009; Volume 3, pp. 265-268. [CrossRef]

21. DAISIE. Species Accounts of 100 of the Most Invasive Alien Species in Europe. In Handbook of Alien Species in Europe; Springer: Dordrecht, The Netherlands, 2009; pp. 269-374. [CrossRef]

22. BBC News. 'Killer' Shrimp is the Worst Alien Invader of Britain's Waterways Which Officials Say Are Costing Billions of Pounds to Tackle. Available online: http:/ / www.bbc.co.uk/news/uk-14428585 (accessed on 1 September 2021).

23. Bacela-Spychalska, K.; Grabowski, M.; Mamos, T.; Rewicz, T. Data about distribution of Dikerogammarus villosus in Masurian Lake District in Poland. Unpublished work. 2021.

24. Burgess, A.; Bojko, J. Microsporidia are coming: Cucumispora ornata and Dictyocoela berillonum invade Northern Britain. BioInvasions Rec. 2021. submitted.

25. Csabai, Z.; Borza, P.; Rewicz, T.; Pernecker, B.; Berta, B.J.; Móra, A. Mass appearance of the Ponto-Caspian invader Pontogammarus robustoides in the River Tisza catchment: Bypass in the southern invasion corridor? Knowl. Manag. Aquat. Ecosyst. 2020, 421, 9. [CrossRef]

26. Moedt, S.; van Haaren, T. Pontogammarus robustoides (Sars, 1894), a new non-indigenous amphipod in the Netherlands (Crustacea: Amphipoda). Lauterbornia 2018, 85, 123-126.

27. Rewicz, T.; Wattier, R.; Grabowski, M.; Rigaud, T.; Bacela-Spychalska, K. Out of the Black Sea: Phylogeography of the invasive killer shrimp Dikerogammarus villosus across Europe. PLoS ONE 2015, 10, e0118121. [CrossRef] [PubMed] 
28. Rewicz, T.; Wattier, R.; Rigaud, T.; Grabowski, M.; Mamos, T.; Baceela-Spychalska, K. The killer shrimp, Dikerogammarus villosus, invading European Alpine Lakes: A single main source but independent founder events with an overall loss of genetic diversity. Freshw. Biol. 2017, 62, 1036-1051. [CrossRef]

29. Wattier, R.A.; Haine, E.R.; Beguet, J.; Martin, G.; Bollache, L.; Musko, I.B.; Platvoet, D.; Rigaud, T. No genetic bottleneck or associated microparasite loss in invasive populations of a freshwater amphipod. Oikos 2007, 116, 1941-1953. [CrossRef]

30. Bacela-Spychalska, K.; Grabowski, M.; Rewicz, T.; Konopacka, A.; Wattier, R. The 'killer shrimp' Dikerogammarus villosus (Crustacea, Amphipoda) invading Alpine lakes: Overland transport by recreational boats and scuba-diving gear as potential entry vectors? Aquat. Conserv. Mar. Freshw. Ecosyst. 2013, 23, 606-618. [CrossRef]

31. Müller, J.C.; Schramm, S.; Seitz, A. Genetic and morphological differentiation of Dikerogammarus invaders and their invasion history in Central Europe. Freshw. Biol. 2002, 47, 2039-2048. [CrossRef]

32. Kobak, J.; Rachalewski, M.; Baccela-Spychalska, K. Conquerors or exiles? Impact of interference competition among invasive Ponto-Caspian gammarideans on their dispersal rates. Biol. Invasions 2016, 18, 1953-1965. [CrossRef]

33. Stebbing, T.R.R. Amphipoda from the Copenhagen Museum and other sources, part II. Trans. Linn. Soc. Lond. Zool. 1899, 2, 395-432. [CrossRef]

34. Sowinsky, V.K. Introduction a l'etude de la faune du bassin marin Ponto-Aralo-Kaspien sous le point de vue d'une province zoo-geographique independante (russ.). Zap. Kiev. Obs. Estestvoispyt. (Mem. Soc. Nat. Kiew) 1904, 18, 1-487.

35. Stock, J.H. The systematics of certain Ponto-Caspian Gammaridae (Crustacea, Amphipoda). Mitt. Hambg. Zool. Mus. Inst. 1974, 70, 75-95.

36. Bousfield, E.L. A new look at the systematics of Gammaridean amphipods of the world. Crustaceana Suppl. 1977, 4, $282-316$.

37. Lowry, J.K.; Myers, A.A. A phylogeny and classification of the Senticaudata subord. nov. Crustacea: Amphipoda. Zootaxa 2013, 3610, 1-80. [CrossRef]

38. Hou, Z.; Sket, B. A review of Gammaridae (Crustacea: Amphipoda): The family extent, its evolutionary history, and taxonomic redefinition of genera. Zool. J. Linn. Soc. 2016, 176, 323-348. [CrossRef]

39. Sket, B.; Hou, Z. Family Gammaridae (Crustacea: Amphipoda), mainly its Echinogammarus clade in SW Europe. Further elucidation of its phylogeny and taxonomy. Acta Biol. Slov. 2018, 61, 93-102.

40. Pjatakova, G.M.; Tarasov, A.G. Caspian Sea amphipods: Biodiversity, systematic position and ecological peculiarities of some species. J. Salt Lake Res. 1996, 5, 63-79. [CrossRef]

41. Morhun, H.; Copilaș-Ciocianu, D.; Rewicz, T.; Son, M.O.; Khomenko, A.; Huseynov, M.; Utevsky, S.; Grabowski, M. Molecular markers and SEM imaging reveal pseudocryptic diversity within the Ponto-Caspian low-profile amphipod invader Dikerogammarus bispinosus. Eur. Zool. J. 2021. submitted.

42. Coordinators, N.R. Database resources of the National Center for Biotechnology Information. Nucleic Acids Res. 2016, 44, D7-D19. [CrossRef]

43. Kao, D.; Lai, A.G.; Stamataki, E.; Rosic, S.; Konstantinides, N.; Jarvis, E.; Di Donfrancesco, A.; Pouchkina-Stancheva, N.; Sémon, M.; Grillo, M.; et al. The genome of the crustacean Parhyale hawaiensis, a model for animal development, regeneration, immunity and lignocellulose digestion. eLife 2016, 5, e20062. [CrossRef] [PubMed]

44. Cormier, A.; Chebbi, M.A.; Giraud, I.; Wattier, R.; Teixeira, M.; Gilbert, C.; Rigaud, T.; Cordaux, R. Comparative genomics of strictly vertically transmitted, feminizing microsporidia Endosymbionts of Amphipod Crustaceans. Genome Biol. Evol. 2021, 13, evaa245. [CrossRef]

45. Salemaa, H.; Kamaltynov, R.M. The chromosome numbers of endemic Amphipoda and Isopoda-An evolutionary paradox in the ancient lakes Ohrid and Baikal. Arch. Fuer Hydrobiol. Ergeb. Limnol. Beih. 1994, 44, 247-256.

46. Caputo, D.R.; Robson, S.C.; Werner, I.; Ford, A.T. Complete transcriptome assembly and annotation of a critically important amphipod species in freshwater ecotoxicological risk assessment: Gammarus fossarum. Environ. Int. 2020, 137, 105319. [CrossRef] [PubMed]

47. Cogne, Y.; Degli-Esposti, D.; Pible, O.; Gouveia, D.; François, A.; Bouchez, O.; Eché, C.; Ford, A.; Geffard, O.; Armengaud, J.; et al. De novo transcriptomes of 14 gammarid individuals for proteogenomic analysis of seven taxonomic groups. Sci. Data 2019, 6, 184. [CrossRef] [PubMed]

48. Gismondi, E.; Thomé, J.P. Transcriptome of the freshwater amphipod Gammarus pulex hepatopancreas. Genom. Data 2016, 8, 91-92. [CrossRef] [PubMed]

49. Naumenko, S.A.; Logacheva, M.D.; Popova, N.V.; Klepikova, A.V.; Penin, A.A.; Bazykin, G.A.; Etingova, A.E.; Mugue, N.S.; Kondrashov, A.S.; Yampolsky, L.Y. Transcriptome-based phylogeny of endemic Lake Baikal amphipod species flock: Fast speciation accompanied by frequent episodes of positive selection. Mol. Ecol. 2017, 26, 536-553. [CrossRef]

50. Cormier, A.; Wattier, R.; Teixeira, M.; Rigaud, T.; Cordaux, R. The complete mitochondrial genome of Gammarus roeselii (Crustacea, Amphipoda): Insights into mitogenome plasticity and evolution. Hydrobiologia 2018, 825, 197-210. [CrossRef]

51. Macher, J.N.; Leese, F.; Weigand, A.M.; Rozenberg, A. The complete mitochondrial genome of a cryptic amphipod species from the Gammarus fossarum complex. Mitochondrial DNA Part B 2017, 2, 17-18. [CrossRef]

52. Romanova, E.V.; Aleoshin, V.V.; Kamaltynov, R.M.; Mikhailov, K.V.; Logacheva, M.D.; Sirotinina, E.A.; Gornov, A.Y.; Anikin, A.S.; Sherbakov, D.Y. Evolution of mitochondrial genomes in Baikalian amphipods. BMC Genom. 2016, 17, 1016. [CrossRef]

53. Boore, J.L. Animal mitochondrial genomes. Nucleic Acids Res. 1999, 27, 1767-1780. [CrossRef] 
54. Aunins, A.W.; Nelms, D.L.; Hobson, C.S.; King, T.L. Comparative mitogenomic analyses of three North American stygobiont amphipods of the genus Stygobromus (Crustacea: Amphipoda). Mitochondrial DNA Part B 2016, 1, 560-563. [CrossRef]

55. Bojko, J. The mitochondrial genome of UK (non-native) Dikerogammarus haemobaphes (Amphipoda: Gammaridae) informs upon Dikerogammarus evolution, invasions and associated microparasites. Hydrobiologia 2020, 847, 229-242. [CrossRef] [PubMed]

56. Lan, Y.; Sun, J.; Bartlett, D.H.; Rouse, G.W.; Tabata, H.G.; Qian, P.-Y. The deepest mitochondrial genome sequenced from Mariana Trench Hirondellea gigas (Amphipoda). Mitochondrial DNA Part B 2016, 1, 802-803. [CrossRef]

57. Pons, J.; Bauzà-Ribot, M.M.; Jaume, D.; Juan, C. Next-generation sequencing, phylogenetic signal and comparative mitogenomic analyses in Metacrangonyctidae (Amphipoda: Crustacea). BMC Genom. 2014, 15, 556. [CrossRef] [PubMed]

58. Krebes, L.; Bastrop, R. The mitogenome of Gammarus duebeni (Crustacea Amphipoda): A new gene order and non-neutral sequence evolution of tandem repeats in the control region. Comp. Biochem. Physiol. Part. D Genom. Proteom. 2012, 7, $201-211$. [CrossRef] [PubMed]

59. Smith, D.R. RNA-Seq data: A goldmine for organelle research. Brief. Funct. Genom. 2013, 12, 454-456. [CrossRef]

60. Dick, J.T.A.; Platvoet, D.; Kelly, D.W. Predatory impact of the freshwater invader Dikerogammarus villosus (Crustacea: Amphipoda). Can. J. Fish. Aquat. Sci. 2002, 59, 1078-1084. [CrossRef]

61. Wattier, R.; Mamos, T.; Copilaş-Ciocianu, D.; Jelić, M.; Ollivier, A.; Chaumot, A.; Danger, M.; Felten, V.; Piscart, C.; Žganec, K.; et al. Continental-scale patterns of hyper-cryptic diversity within the freshwater model taxon Gammarus fossarum (Crustacea, Amphipoda). Sci. Rep. 2020, 10, 16536. [CrossRef]

62. Blackman, R.C.; Mächler, E.; Altermatt, F.; Arnold, A.; Beja, P.; Boets, P.; Egeter, B.; Elbrecht, V.; Filipe, A.F.; Jones, J.I.; et al. Advancing the use of molecular methods for routine freshwater macroinvertebrate biomonitoring-The need for calibration experiments. Metabarcoding Metagenomics 2019, 3, e34735. [CrossRef]

63. Gold, Z.; Sprague, J.; Kushner, D.J.; Zerecero Marin, E.; Barber, P.H. eDNA metabarcoding as a biomonitoring tool for marine protected areas. PLoS ONE 2021, 16, e0238557. [CrossRef] [PubMed]

64. Pawlowski, J.; Bonin, A.; Boyer, F.; Cordier, T.; Taberlet, P. Environmental DNA for biomonitoring. Mol. Ecol. 2021, 30, 2931-2936. [CrossRef]

65. Windisch, U.; Springer, F.; Stahl, T. Freshwater amphipods (Gammarus pulex/fossarum) and brown trout as bioindicators for PFC contamination with regard to the aquatic ecological status of a small stream. Environ. Sci. Eur. 2020, 32, 108. [CrossRef]

66. Džeroski, S.; Demšar, D.; Grbović, J. Predicting chemical parameters of river water quality from bioindicator data. Appl. Intell. 2000, 13, 7-17. [CrossRef]

67. Lagrue, C.; Wattier, R.; Galipaud, M.; Gauthey, Z.; Rullmann, J.-P.; Dubreuil, C.; Rigaud, T.; Bollache, L. Confrontation of cryptic diversity and mate discrimination within Gammarus pulex and Gammarus fossarum species complexes. Freshw. Biol. 2014, 59, 2555-2570. [CrossRef]

68. Weiss, M.; Macher, J.N.; Seefeldt, M.A.; Leese, F. Molecular evidence for further overlooked species within the Gammarus fossarum complex (Crustacea: Amphipoda). Hydrobiologia 2014, 721, 165-184. [CrossRef]

69. Boore, J.L.; Lavrov, D.V.; Brown, W.M. Gene translocation links insects and crustaceans. Nature 1998, 392, 667-668. [CrossRef]

70. Csapó, H.; Krzywoźniak, P.; Grabowski, M.; Wattier, R.; Bącela-Spychalska, K.; Mamos, T.; Jelić, M.; Rewicz, T. Successful post-glacial colonization of Europe by single lineage of freshwater amphipod from its Pannonian Plio-Pleistocene diversification hotspot. Sci. Rep. 2020, 10, 18695. [CrossRef] [PubMed]

71. Schmidt, T.L.; van Rooyen, A.R.; Chung, J.; Endersby-Harshman, N.M.; Griffin, P.C.; Sly, A.; Hoffmann, A.A.; Weeks, A.R. Tracking genetic invasions: Genome-wide single nucleotide polymorphisms reveal the source of pyrethroid-resistant Aedes aegypti (yellow fever mosquito) incursions at international ports. Evol. Appl. 2019, 12, 1136-1146. [CrossRef]

72. Taylor, A.T.; Bangs, M.; Long, J.M. Sibship reconstruction with SNPs illuminates the scope of a cryptic invasion of Asian Swamp Eels (Monopterus albus) in Georgia, USA. Biol. Invasions 2020, 23, 569-580. [CrossRef]

73. Wu, Y.; Bogdanowicz, S.M.; Andres, J.A.; Vieira, K.A.; Wang, B.; Cossé, A.; Pfister, S.E. Tracking invasions of a destructive defoliator, the gypsy moth (Erebidae: Lymantria dispar): Population structure, origin of intercepted specimens, and Asian introgression into North America. Evol. Appl. 2020, 13, 2056-2070. [CrossRef]

74. Rius, M.; Bourne, S.; Hornsby, H.G.; Chapman, M. Applications of next-generation sequencing to the study of biological invasions. Curr. Zool. 2015, 61, 488-504. [CrossRef]

75. Schellenberg, A. Schlüssel und Diagnosen der dem Süsswasser-Gammarus nahestehenden Einheiten ausschliesslich der Arten des Baikalseses und Australiens. Zool. Anz. 1937, 117, 267-280.

76. Copilaş-Ciocianu, D.; Sidorov, D.; Gontcharov, A. Adrift across tectonic plates: Molecular phylogenetics supports the ancient Laurasian origin of old limnic crangonyctid amphipods. Org. Divers. Evol. 2019, 19, 191-207. [CrossRef]

77. Derzhavin, A. Notes on the Upper Sarmatian amphipods of the Ponto-Caspian region. Bull. Soc. Nat. Moscou 1927, 2, 183-196.

78. Zettler, M.L.; Zettler, A. Marine and Freshwater Amphipoda from the Baltic Sea and Adjacent Territories; ConchBooks: Harxheim, Gemany, 2017.

79. Grabowski, M.; Rewicz, T.; Bacela-Spychalska, K.; Konopacka, A.; Mamos, T.; Jazdzewski, K. Cryptic invasion of Baltic lowlands by freshwater amphipod of Pontic origin. Aquat. Invasions 2012, 7, 337-346. [CrossRef]

80. Andrews, S. FastQC: A Quality Control Tool for High Throughput Sequence Data. Available online: https://www.bioinformatics. babraham.ac.uk/projects/fastqc/ (accessed on 1 September 2021). 
81. Bolger, A.M.; Lohse, M.; Usadel, B. Trimmomatic: A flexible trimmer for Illumina sequence data. Bioinformatics 2014, 30, 2114-2120. [CrossRef]

82. Hahn, C.; Bachmann, L.; Chevreux, B. Reconstructing mitochondrial genomes directly from genomic next-generation sequencing reads-A baiting and iterative mapping approach. Nucleic Acids Res. 2013, 41, e129. [CrossRef] [PubMed]

83. Dierckxsens, N.; Mardulyn, P.; Smits, G. NOVOPlasty: De novo assembly of organelle genomes from whole genome data. Nucleic Acids Res. 2017, 45, e18.

84. Langmead, B.; Salzberg, S.L. Fast gapped-read alignment with Bowtie 2. Nat. Methods 2012, 9, 357-359. [CrossRef]

85. Lubośny, M.; Przyłucka, A.; Śmietanka, B.; Burzyński, A. Semimytilus algosus: First known hermaphroditic mussel with doubly uniparental inheritance of mitochondrial DNA. Sci. Rep. 2020, 10, 11256. [CrossRef]

86. Grabherr, M.G.; Haas, B.J.; Yassour, M.; Levin, J.Z.; Thompson, D.A.; Amit, I.; Adiconis, X.; Fan, L.; Raychowdhury, R.; Zeng, Q. Full-length transcriptome assembly from RNA-Seq data without a reference genome. Nat. Biotechnol. 2011, $29,644-652$. [CrossRef]

87. Birney, E.; Clamp, M.; Durbin, R. GeneWise and genomewise. Genome Res. 2004, 14, 988-995. [CrossRef]

88. Nawrocki, E.P.; Eddy, S.R. Infernal 1.1:100-fold faster RNA homology searches. Bioinformatics 2013, 29, 2933-2935. [CrossRef] [PubMed]

89. Li, H.; Durbin, R. Fast and accurate short read alignment with Burrows-Wheeler transform. Bioinformatics 2009, 25, 1754-1760. [CrossRef] [PubMed]

90. Geneious 11.1. Available online: https://www.geneious.com (accessed on 1 September 2021).

91. Katoh, K.; Standley, D.M. MAFFT multiple sequence alignment software version 7: Improvements in performance and usability. Mol. Biol. Evol. 2013, 30, 772-780. [CrossRef]

92. Raden, M.; Ali, S.M.; Alkhnbashi, O.S.; Busch, A.; Costa, F.; Davis, J.A.; Eggenhofer, F.; Gelhausen, R.; Georg, J.; Heyne, S.; et al. Freiburg RNA tools: A central online resource for RNA-focused research and teaching. Nucleic Acids Res. 2018, 46, W25-W29. [CrossRef] [PubMed]

93. Bouckaert, R.; Heled, J.; Kühnert, D.; Vaughan, T.; Wu, C.-H.; Xie, D.; Suchard, M.A.; Rambaut, A.; Drummond, A.J. BEAST 2: A software platform for Bayesian evolutionary analysis. PLoS Comput. Biol. 2014, 10, e1003537. [CrossRef] [PubMed]

94. Copilaş-Ciocianu, D.; Petrusek, A. Phylogeography of a freshwater crustacean species complex reflects a long-gone archipelago. J. Biogeogr. 2017, 44, 421-432. [CrossRef]

95. Grabowski, M.; Mamos, T.; Bącela-Spychalska, K.; Rewicz, T.; Wattier, R.A. Neogene paleogeography provides context for understanding the origin and spatial distribution of cryptic diversity in a widespread Balkan freshwater amphipod. PeerJ 2017, 5, e3016. [CrossRef]

96. Mamos, T.; Wattier, R.; Burzyński, A.; Grabowski, M. The legacy of a vanished sea: A high level of diversification within a European freshwater amphipod species complex driven by 15 my of Paratethys regression. Mol. Ecol. 2016, 25, 795-810. [CrossRef]

97. Bouckaert, R.R.; Drummond, A.J. bModelTest: Bayesian phylogenetic site model averaging and model comparison. BMC Evol. Biol. 2017, 17, 42. [CrossRef]

98. Rambaut, A.; Drummond, A.J.; Xie, D.; Baele, G.; Suchard, M.A. Posterior summarization in Bayesian phylogenetics using Tracer 1.7. Syst. Biol. 2018, 67, 901. [CrossRef]

99. Stamatakis, A. RAxML version 8: A tool for phylogenetic analysis and post-analysis of large phylogenies. Bioinformatics 2014, 30, 1312-1313. [CrossRef] [PubMed] 